Article

\title{
Hypothalamic-Pituitary and Adipose Tissue Responses to the Effect of Resistin in Sheep: The Integration of Leptin and Resistin Signaling Involving a Suppressor of Cytokine Signaling 3 and the Long Form of the Leptin Receptor
}

\author{
Dorota Anna Zieba ${ }^{1, *,+}{ }^{\mathbb{D}}$, Weronika Biernat ${ }^{1,+}$, Malgorzata Szczesna ${ }^{1}$, Katarzyna Kirsz ${ }^{1}$ and \\ Tomasz Misztal ${ }^{2}$ (D) \\ 1 Department of Animal Biotechnology, Laboratory of Biotechnology and Genomics, University of Agriculture \\ in Krakow, 30-248 Krakow, Poland \\ 2 Department of Animal Physiology, The Kielanowski Institute of Animal Physiology and Nutrition, \\ Polish Academy of Sciences, Instytucka 3, 05-110 Jabłonna, Poland \\ * Correspondence: rzzieba@cyf-kr.edu.pl; Tel.: +48-12-429-72-24 \\ + In the Authors Opinion, Dorota A. Zieba and Weronika Biernat should be Considered as Equal First Authors \\ of the Paper.
}

Received: 11 July 2019; Accepted: 6 September 2019; Published: 11 September 2019

check for updates

\begin{abstract}
We hypothesized that resistin is engaged in the development of leptin central insensitivity/resistance in sheep, which is a unique animal model to explore reversible leptin resistance. Thirty Polish Longwool ewes, which were ovariectomized with estrogen replacement, were used. Treatments consisted of the intravenous injection of control (saline) or recombinant bovine resistin (rbresistin): control (Control; $n=10)$, a low dose of rbresistin (R1; $1.0 \mu \mathrm{g} / \mathrm{kg}$ body weight $(\mathrm{BW}) ; n=10)$, and a high dose of rbresistin (R2; $10.0 \mu \mathrm{g} / \mathrm{kg} \mathrm{BW} ; n=10)$. The studies were performed during short-day (SD) and long-day (LD) photoperiods. Leptin and resistin concentrations were determined. Expression levels of a suppressor of cytokine signaling (SOCS)-3 and the long form of the leptin receptor (LeptRb) were determined in selected brain regions, including in the anterior pituitary (AP), hypothalamic arcuate nucleus (ARC), preoptic area (POA), and ventro- and dorsomedial nuclei (VMH/DMH). The results indicate that resistin induced a consistent decrease in LeptRb (except in POA) and an increase in SOCS-3 expression during the LD photoperiod in all selected brain regions. In conclusion, the results demonstrate that the action of resistin appears to be strongly associated with photoperiod-driven changes in the leptin signaling pathway, which may underlie the phenomenon of central leptin resistance.
\end{abstract}

Keywords: leptin; leptin receptor; leptin resistance; photoperiod; resistin; sheep; SOCS-3

\section{Introduction}

Sheep, which have strong seasonal breeding features, are characterized by circannual rhythms for the secretion of many hormones, food intake and body weight (BW), which makes them an elegant animal example for determining neuroendocrine adaptations of animals to challenging environmental conditions [1]. One such adaptation is the development of leptin resistance/insensitivity. In endocrinology, the phenomenon in which the concentration of a regulatory hormone is high with a lack of response to its action is termed resistance syndrome [2]. Four mechanisms for leptin resistance have been proposed: (1) a decrease in leptin transport from the bloodstream to the hypothalamus (termed peripheral resistance), (2) desensitization of leptin receptors (termed central resistance), 
(3) suppression of the long isoform of the leptin receptor (LeptRb)-associated signaling pathways by negative regulators such as a suppressor of cytokine signaling (SOCS)-3 (also termed central resistance), and (4) hypothalamic inflammation, which alters the neuronal pathway involved in energy homeostasis [3]. Sheep represent a unique animal model to explore reversible central leptin insensitivity because the ovine hypothalamus and pituitary are resistant to leptin during predictable seasons $[4,5]$. Since 2004, studies by our laboratory have focused mainly on central leptin resistance caused by the elevated expression of SOCS-3 during the long-day (LD) season [6,7]. Despite the importance of this phenomenon in other species, including humans, as one of the main factors that play a role in the development of metabolic diseases [8], further in-depth experiments are required to elucidate leptin resistance and understand its mechanisms. If significant changes in seasonal leptin insensitivity occur at the hypothalamic-pituitary level in sheep [5,7], questions arise regarding how this effect is mediated.

In the last two decades, numerous adipose-secreted proteins have been shown to behave as hormones and control glucose metabolism and reproductive processes. Leptin has attracted the attention of most of our group since its discovery by Friedman in $1994[9,10]$. This protein, which is consecutively secreted in response to hyperinsulinemia after a meal, reduces appetite, increases energy output, acts at all hypothalamic-pituitary-gonad levels and regulates reproduction. In contrast, resistin, another adipocyte-secreted hormone, induces insulin resistance and hypothalamic leptin insensitivity and strongly increases circulating leptin concentrations in transgenic mice with moderate adipocyte-specific resistin overexpression [11]. Recently, studies by Biernat et al. [12] and Dall'Aglio et al. [13] showed that resistin is engaged in LH (luteinizing hormone) and PRL (prolactin) secretion and uterine function in sheep.

Leptin and resistin both operate on the level of the central nervous system to regulate metabolic processes, suggesting the activation of a few common signaling pathways. A primary site of leptin activity and localization of LeptRb is the arcuate nucleus (ARC) of the hypothalamus [14], but other hypothalamic nuclei are also under the influence of leptin, as shown by research involving microinjections of leptin or demonstrating the spread of its receptor [15,16]. In contrast, the site of action of resistin in the brain has not been thoroughly investigated. However, potential sites of activity were examined using Fos protein detection as a marker of activated neurons $[17,18]$. These studies suggest that leptin and resistin can activate the same nuclei in the hypothalamus and the medulla [17].

This paper addresses the important question of whether resistin is able to affect leptin secretion from adipose tissue or leptin signaling at the level of the hypothalamus and adenohypophysis and as a result, contribute to the progression of the leptin resistance phenomenon in sheep. Data from other studies have indicated that resistin mediates central leptin resistance in rodents [11] and activates SOCS-3 [19]. Taking into account our previous studies highlighting the role of SOCS-3 in the creation of leptin's seasonal and pregnancy-induced central resistance in sheep [6,7], we hypothesized that resistin could be a factor that leads to decreased tissue sensitivity to leptin by affecting SOCS-3 and thus LeptRb expression. To verify this hypothesis, the expression of SOCS-3 and LeptRb was determined in selected brain regions: the anterior pituitary (AP), the hypothalamic ARC, the ventro- and dorsomedial nuclei $(\mathrm{VMH} / \mathrm{DMH})$, and the preoptic area (POA). Furthermore, in the in vitro experiments, we examined the direct influence of resistin on the secretion of leptin by adipose tissue explants. In these studies, we have also returned attention to the effect of photoperiod, which plays a predominant role in the physiology of seasonally breeding animals.

\section{Materials and Methods}

\subsection{Animals and Experimental Procedures}

The Second Local Ethics Committee on Animal Testing in Krakow, Poland, approved all procedures conducted on animals during the experiments (Protocol No. 109/2018).

A total of thirty Polish Longwool ewes, a breed that exhibits strong seasonal reproduction, were prepared for experiments (ovarectomized with estrogen replacement) as described in detail by 
Biernat et al. [12]. The animals were aged from 2 to 3 years, weighing $64 \pm 4 \mathrm{~kg}$, and were kept in individual pens under natural environmental conditions (longitude: $19^{\circ} 57 \mathrm{E}$, latitude: $50^{\circ} 04 \mathrm{~N}$ ). The body condition score of the sheep was calculated (BCS $=3$, on a scale of 1 to 5) [20], and the animals were fed twice a day at 07:00 and 16:00 with a diet developed to provide 100\% of the National Research Institute of Animal Production recommendations for maintenance [21], with constant access to water.

\subsection{Experimental Design}

In both photoperiodic seasons, LD in May and short day (SD) in November, ewes ( $n=15 /$ season) were randomly assigned to one of three treatment groups ( $n=5 /$ group/season) and then placed frequently into carts according to a previous report to avoid stress during the experiment [7]. Recombinant bovine resistin (rbresistin) was purchased from CliniSciences (Nanterre, France). The experimental groups were as follows: (1) Control, injected with saline $(n=10)$; (2) R1, injected with a low dose of rbresistin $(1.0 \mu \mathrm{g} / \mathrm{kg}$ of body weight $(\mathrm{BW}) ; n=10)$; and (3) R2, injected with a high dose of rbresistin $(10.0 \mu \mathrm{g} / \mathrm{kg} \mathrm{BW} ; n=10)$. The rbresistin doses were chosen based on our previous study [12]. In the morning on the day of each experiment, five randomly chosen sheep were fitted with jugular vein catheters (Central and Peripheral Venous Catheters, Careflow ${ }^{\mathrm{TM}}$, Argon, Billmed Sp. $\mathrm{z}$ o.o., Warsaw, Poland). At the beginning of the experiment (time 0 ), saline/rbresistin was injected through the catheter, and $1 \mathrm{~h}$ later, blood was collected through the same catheter. Blood samples $(5 \mathrm{~mL})$ were dispensed into test tubes containing $150 \mu \mathrm{L}$ of a solution containing heparin $(10,000 \mathrm{IU} / \mathrm{mL})$ and $5 \%(w / v)$ EDTA (Ethylene Diamine Tetraacetic) and placed on ice immediately. Plasma was separated by centrifugation and stored at $-20^{\circ} \mathrm{C}$ until estradiol, resistin, and leptin analyses.

In each photoperiodic season, $1 \mathrm{~h}$ after saline/rbresistin infusion and blood sample collection, the animals were humanely euthanized by captive bolt stunning. From the Control group of ewes, perirenal adipose tissue was collected for in vitro experiments. Brains with the infundibulum remaining intact were rapidly removed from the skulls of all ewes and frozen on dry ice. Samples of the AP, the hypothalamic ARC, the $\mathrm{VMH} / \mathrm{DMH}$, and the POA, were aseptically isolated from the ewes $10-15 \mathrm{~min}$ postmortem. The selected brain regions were collected by removing a tissue block encompassing the hypothalamic-infundibular complex, followed by transection into two halves. An anterior coronal cut was made $\sim 3-5 \mathrm{~mm}$ rostral to the optic chiasm, and a posterior coronal cut was made, which contained approximately one-third of the mamillary body. A longitudinal cut parallel to the ventral surface of the brain $\sim 2-3 \mathrm{~cm}$ dorsal to the anterior commissure followed. At the same time, the pituitary was harvested from the sella turcica. Isolated tissues were frozen immediately on dry ice for storage at $-80^{\circ} \mathrm{C}$. The probability of contamination caused by transferring tissue between samples was eliminated using separate sterile instruments to dissect the chosen area. Samples of brain tissue were rinsed in phosphate-buffered saline (PBS; Laboratory of Vaccines, Lublin, Poland), snap-frozen in liquid nitrogen, and then stored at $-80^{\circ} \mathrm{C}$ until analysis.

Adipose Tissue Preparation and Incubation

Perirenal adipose tissue was aseptically collected from 5 ewes from the Control group per season. Fragments of tissue were transported to the laboratory at $4{ }^{\circ} \mathrm{C}$ in Eagle's sterile medium (Biomed, Lublin, Poland) supplemented with antibiotics (100 $\mu \mathrm{L} / 100 \mathrm{~mL}$ Antibiotic/Antimycotic Solution, SIGMA Chemical Co., St. Louis, USA). Each tissue sample was rinsed three times in Eagle's medium with antibiotics. The adipose tissue was divided into small pieces, weighing approximately $100 \mathrm{mg}$ each. Then, the samples were randomly assigned to 6-well Corning tissue culture plates (Corning Glass Works, New York, USA) with $2.5 \mathrm{~mL}$ of Eagle's medium. Incubation was performed in a 95\% humidified air and $5 \% \mathrm{CO}_{2}$ atmosphere at $37{ }^{\circ} \mathrm{C}$ for a total of $4.0 \mathrm{~h}$. After a 60 min equilibration period, explants were treated with 0 (Control), 1, 10,100, or $1000 \mathrm{ng} / \mathrm{mL}$ doses of rbresistin. The doses of rbresistin were chosen based on a paper by Spicer et al. [22]. All of the treatments were cultured in triplicate, and incubation continued for another $3.0 \mathrm{~h}$. At the end of incubation, one milliliter of 
medium was collected. Media samples were stored at $-20^{\circ} \mathrm{C}$ until they were radioimmunoassayed (RIA) for leptin.

\subsection{Hormone Assays}

Concentrations of estradiol in plasma were determined using an ELISA kit (Enzyme-linked immunosorbent assay kit) (DRG Instruments $\mathrm{GmbH}$, Marburg, Germany) according to the manufacturer's instructions. The inter- and intra-assay precision values exhibited CVs (the coefficient of variations) of $3.9 \%$ and $2.6 \%$, respectively, and the assay sensitivity was $1.9 \mathrm{pg} / \mathrm{mL}$. Resistin concentrations were determined using commercially available EIA kits (Cloud-Clone Corp., Katy, USA) according to the manufacturer's instructions. The inter- and intra-assay precision values exhibited CVs of $6.6 \%$ and $2.3 \%$, respectively, and the assay sensitivity was $4.2 \mathrm{pg} / \mathrm{mL}$.

A highly specific ovine leptin RIA using a high-affinity anti-ovine leptin rabbit antibody, anti-rabbit- $\gamma$-globulin antisera (double-antibody method) and a recombinant ovine leptin standard as described by Delavaud et al. [23] was employed to determine the leptin concentrations in media and plasma. The sensitivity of the assay was $0.3 \mathrm{ng} / \mathrm{mL}$, the intra-assay coefficient of variation was $2.4 \%$, and the interassay coefficient of variation was $10.7 \%$.

\subsection{Hormone Statistical Analysis}

Data analysis was performed by a series of two-way ANOVAs using SigmaPlot ${ }^{\circledR}$ statistical software (version 11.0; Systat Software Inc., Richmond, CA, USA), preceded by Grubb's test to identify outliers. The statistical models included the main effects of peptide treatment and season. All data sets with failed tests of normality and/or equal variance were transformed as natural logarithms. If the main effects or their interactions were significant, the Holm-Sidak test was used as a post-ANOVA test to compare individual means. A $P$ value $<0.05$ was considered to indicate statistical significance. The results are given as the mean \pm SEM.

\subsection{Molecular Analysis}

The expression of LeptRb and SOCS-3 was measured using the Real-Time PCR method. Tissue homogenization was performed with a rotor-stator homogenizer (Omni TH, Omni International, Inc., Kennesaw, GA, USA) and single-use tips (Soft Tissue Omni Tip Plastic Homogenizing Probes, Omni International, Inc.). Total RNA was isolated using TRIzol reagent (Ambion Inc., Austin, TX, USA) following the manufacturer's protocol. Incubation of samples at $42{ }^{\circ} \mathrm{C}$ for $2 \mathrm{~min}$ with gDNA Wipeout Buffer (QuantiTect Reverse Transcription Kit; Qiagen, Hilden, Germany) was used to eliminate contamination of genomic DNA. Subsequently, to obtain samples of cDNAs by reverse transcription, isolates of RNA $(1 \mu \mathrm{g})$ were incubated with Quantiscript reverse transcriptase and RT primer mix (QuantiTect Reverse Transcription Kit; as above) at $42^{\circ} \mathrm{C}$ for $15 \mathrm{~min}$. The reaction was terminated by heating the samples to $94^{\circ} \mathrm{C}$ for $3 \mathrm{~min}$. Amplification of each cDNA was performed in triplicate using an Applied Biosystems 7300 Real-Time PCR System, TaqMan Gene Expression Master Mix, $900 \mathrm{nM}$ concentrations of specific primers corresponding to the target/reference genes (Sequence Detection Primers) and $250 \mathrm{nM}$ concentrations of specific probes corresponding to the target/reference genes (TaqMan MGB Probes) supplied by Life Technologies (Foster City, CA, USA). Primers and probes were designed using Primer Express software v. 2.0 (Applied Biosystems; Foster City, CA, USA) and are characterized in Table 1. The thermal profile of the real-time PCR was as follows: (1) $50{ }^{\circ} \mathrm{C}$ for $2 \mathrm{~min}$-initial incubation, (2) $95^{\circ} \mathrm{C}$ for $10 \mathrm{~min}$-activation of polymerase, and (3) 40 cycles with denaturation $\left(95^{\circ} \mathrm{C}\right.$ for $\left.15 \mathrm{sec}\right)$ and annealing/elongation $\left(60^{\circ} \mathrm{C}\right.$ for $\left.60 \mathrm{sec}\right)$. The collected data were recorded with the Applied Biosystem 7300 Real-Time PCR System SDS software. 
Table 1. Characteristics of primers and probes used to determine cyclophilin ( $\mathrm{CPH}$; reference gene), the long form of the leptin receptor (LeptRb; target gene), and a suppressor of cytokine signaling- 3 (SOCS-3; target gene) mRNA expression in sheep.

\begin{tabular}{ccccc}
\hline Gene & Primer Sequence $\left(5^{\prime}-\mathbf{3}^{\prime}\right)$ & Probe Sequence $\left(5^{\prime}-\mathbf{3}^{\prime}\right)$ & $\begin{array}{c}\text { Amplicon } \\
\text { Size }\end{array}$ & $\begin{array}{c}\text { GenBank } \\
\text { Accession } \\
\text { Number }\end{array}$ \\
\hline CPH & $\begin{array}{c}\text { CGGCTCCCAGTTCTTCATCA } \\
\text { ACTACGTGCTTCCATCCAAA }\end{array}$ & FAM-CGTTCCGACTCCGC-MGB & $64 \mathrm{bp}$ & D14074 \\
\hline LeptRb & $\begin{array}{c}\text { CGACGAGGGTGGCATATTTAA } \\
\text { CAGACATAACCTGTGAGGATGGAA }\end{array}$ & FAM-CAGGAGACAGCCCTC-MGB & $63 \mathrm{bp}$ & U62124.1 \\
\hline SOCS-3 & $\begin{array}{c}\text { CCTCAAGACCTTCAGCTCCAA } \\
\text { CTTGCGCACTGCGTTCAC }\end{array}$ & FAM-AGCGAGTACCAGCTGG-MGB & $68 \mathrm{bp}$ & NM_174466 \\
\hline
\end{tabular}

\subsection{Molecular Data Analysis}

The expression levels were calculated using relative quantification (RQ) analysis, and the results were expressed as a function of the threshold cycle $(\mathrm{Ct})$, which is a value corresponding to the fractional PCR cycle number at which the fluorescent signal reached the detection threshold. Data were analyzed using the $2^{-\Delta \Delta C t}$ method, and $C t$ values were converted to fold-change $R Q$ values. The $R Q$ values from each gene were used to compare target gene expression across all groups. The mean mRNA expression levels for target genes in each sample were standardized against the expression of a reference gene (cyclophilin; $\mathrm{CPH}$ ) and expressed relative to the calibrator sample. The variation in the $\mathrm{Ct}$ values for $\mathrm{CPH}$ among the treatment groups was not significant $(P>0.05)$. The mean $\Delta \mathrm{Ct}$ value for tissue collected from the control group was used as a calibrator to compare the changes in target gene expression among all treatment groups in the indicated season.

Differences in the means were compared with SigmaPlot statistical software (version 11.0; Systat Software Inc., Richmond, CA, USA), using all pairwise multiple comparison procedures (Tukey test), preceded by the determination of a significant F-value. Differences were considered statistically significant when $P<0.05$.

\section{Results}

\subsection{Hormone Concentrations}

\subsubsection{Estradiol Concentrations}

The mean circulating concentration of estradiol (mean \pm SEM) was $3.6 \pm 0.3 \mathrm{pg} / \mathrm{mL}$.

\subsubsection{Resistin Concentrations}

The mean concentration of circulating resistin (mean \pm SEM) in the control group of sheep was $7.8 \pm 0.1 \mathrm{ng} / \mathrm{mL}$. The injection of $1.0 \mu \mathrm{g} / \mathrm{kg}$ BW of rbresistin increased $(P<0.05)$ the concentration to $9.5 \pm 0.2 \mathrm{ng} / \mathrm{mL}$, and the $10.0 \mu \mathrm{g} / \mathrm{kg}$ BW dose of rbresistin elevated the concentration of resistin to $15.2 \pm 0.3 \mathrm{ng} / \mathrm{mL}(P<0.01)$. No difference was observed in circulating resistin concentrations between the $\mathrm{LD}$ and SD seasons $(P=0.08)$.

\subsubsection{Leptin Concentrations in Plasma and Media}

Within the Control and all treatment groups, the mean leptin concentration (mean \pm SEM) was significantly higher $(P<0.001)$ during the LD season than during the SD season (Figure 1$)$. During the LD season, a lower dose of rbresistin increased the mean leptin concentration compared to the concentrations observed in the Control group $(P<0.001)$ and R2 group $(P<0.001)$. A higher dose of rbresistin increased the circulating leptin concentration compared to that in the Control group $(P<0.001)$; however, the concentration of leptin in that group after resistin treatment was lower than 
that in the group treated with a lower dose $(P<0.01)$. During the SD season, low and high doses of resistin increased the concentration of leptin $(P<0.001)$ compared to the Control group (Figure 1$)$.

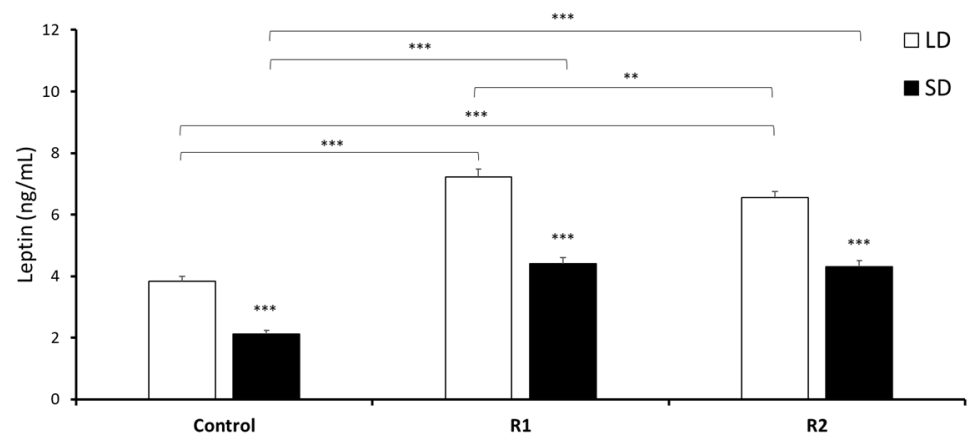

Figure 1. Plasma leptin concentrations. Mean circulating concentrations ( \pm SEM) of leptin in saline- and recombinant bovine resistin-treated groups (R1-low dose and R2-high dose) during the long-day (LD) and short-day (SD) photoperiods. Differences relative to the control or between the other groups are indicated with ${ }^{* *} P<0.01$ or ${ }^{* *} P<0.001$.

The mean overall concentration of leptin (mean \pm SEM) in perirenal adipose tissue explant media was $2.4 \pm 0.1 \mathrm{ng} / \mathrm{mL}$ and was not affected by season $(P=0.9)$ or culture replicate. Moreover, rbresistin had no stimulatory effect $(P=0.2)$ on leptin secretion during the SD season (Figure 2$)$. During the LD season, however, rbresistin at a dose of $1000 \mathrm{ng} / \mathrm{mL}$ stimulated a 3.0-fold increase $(P<0.001)$ in leptin secretion compared to the Control and the other rbresistin-treated explant groups cultured from perirenal adipose tissues (Figure 2).

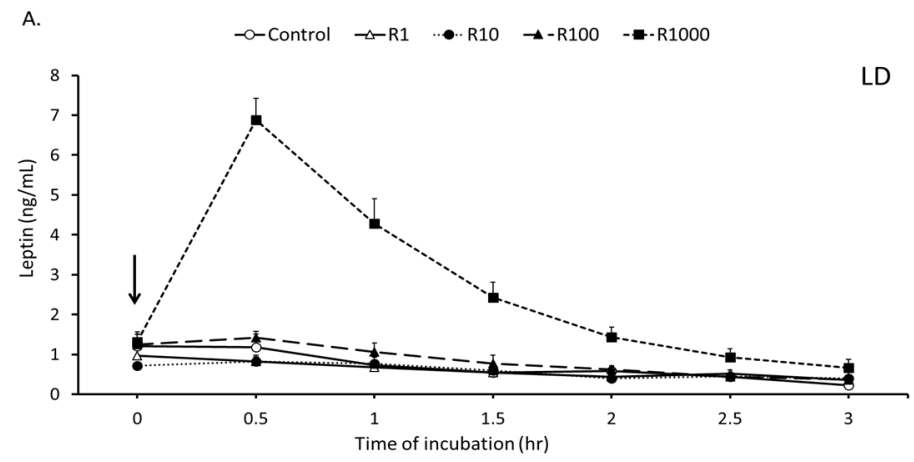

B.

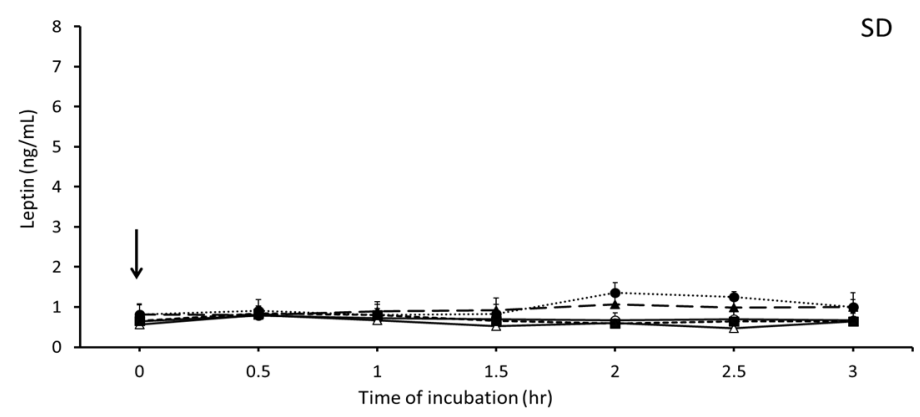

Figure 2. Medium leptin concentrations. Mean concentrations $( \pm$ SEM) of leptin in media collected during a $3.0 \mathrm{~h}$ incubation of ovine perirenal adipose tissue explants obtained during long-day (LD) (panel A) and short-day (SD) (panel B) photoperiods. Adipose tissue explants were incubated with medium containing bovine recombinant resistin $(1,10,100$, or $1000 \mathrm{ng} / \mathrm{mL})$ or medium without hormonal supplementation (Control). Arrows denote 0 (control) h or rbresistin treatment. 


\subsubsection{Leptin Receptor (LeptRb) Expression}

In the pituitary leptin receptor, the transcript level increased 2.1-fold $(P<0.001)$ in the R1-group and 1.8-fold $(P \geq 0.05)$ in the R2-group in the LD season. No significant changes $(P \geq 0.05)$ in pituitary Lept $R b$ expression were found between the groups during the SD season (Figure 3). LeptRb transcripts were detected at varying levels in all examined hypothalamic tissues: the ARC, POA, and VMH/DMH during both the LD and SD seasons (Figure 3). During the LD season, within the ARC, LeptRb mRNA levels decreased after rbresistin injection at a high dose compared to the levels noted in the Control $(P<0.05)$ and $\mathrm{R} 1(P<0.001)$ groups. No differences $(P \geq 0.05)$ were observed during the SD season. Only during the SD season, LeptRb transcripts in the POA increased 8-fold in the R1 $(P<0.001)$ group and 4-fold in the R2 $(P<0.05)$ group compared to the Control group; however, the expression level of LeptRb was 2.2-fold lower in the R2 group $(P<0.001)$ than in the R1-group. The expression of LeptRb in the VMH/DMH decreased in both the R1 $(P<0.001)$ and R2 groups $(P<0.001)$ during the SD season and in response to $\mathrm{R} 2$ treatment $(P<0.001)$ during the $\mathrm{LD}$ season.

\section{A.}

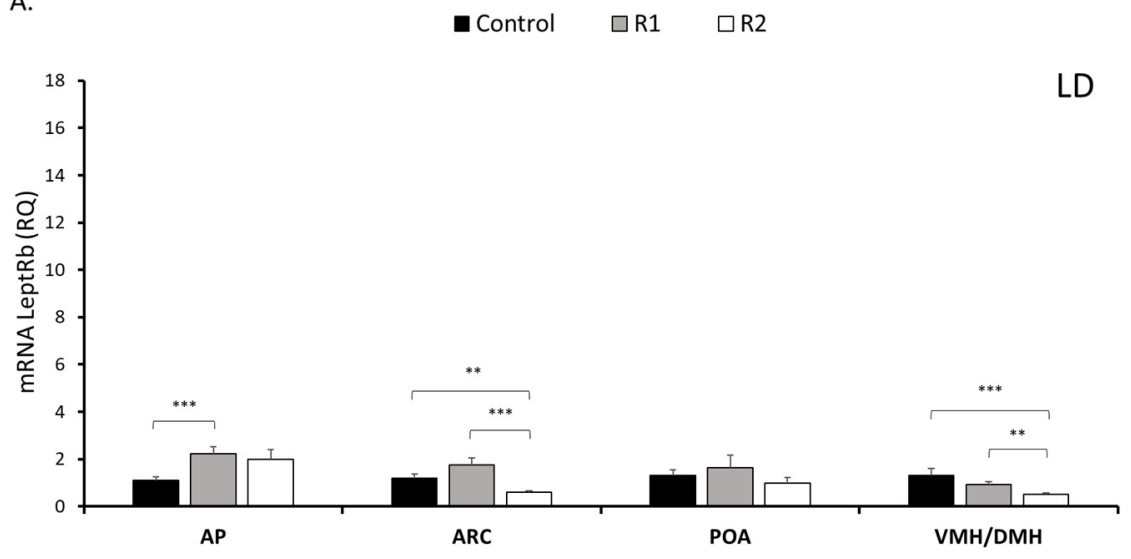

B.

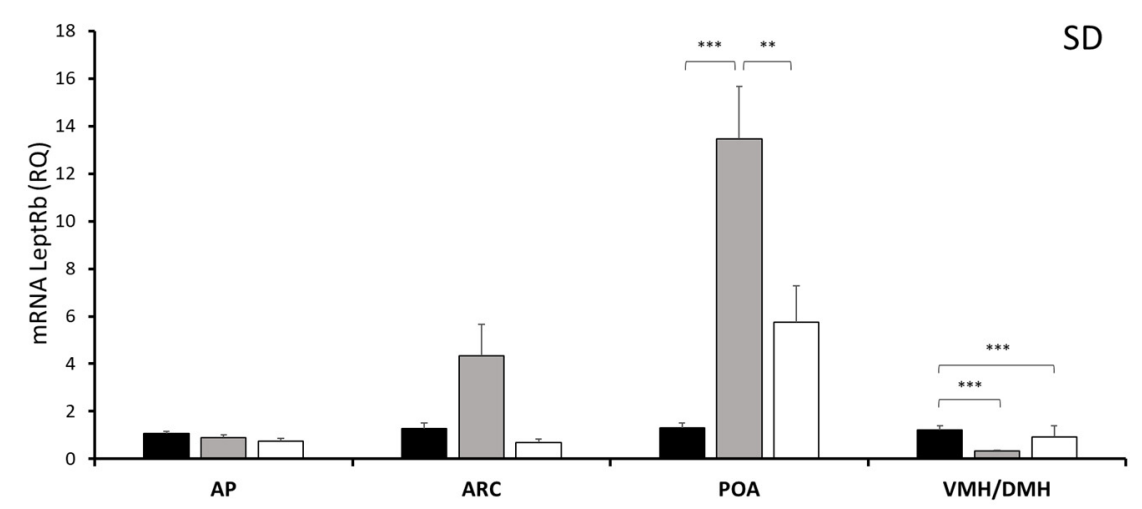

Figure 3. Leptin receptor expression. The mean mRNA expression $( \pm \mathrm{SEM})$ of the long form of the leptin receptor (LeptRb) in the ovine anterior pituitary gland (AP), arcuate nucleus (ARC), preoptic area (POA) and ventro- and dorsomedial nuclei (VMH/DMH) collected during long-day (LD) (panel (A)) and short-day (SD) (panel (B)) photoperiods. The expression of LeptRb mRNA is reported in arbitrary units $(\mathrm{RQ})$ relative to cyclophilin mRNA expression and expressed relative to the calibrator sample. Differences relative to the control or between the other groups are indicated with ${ }^{* *} P<0.01$ or *** $P<0.001$.

\subsubsection{SOCS-3 Expression}

In the AP, SOCS-3 transcript levels in the R2 group increased 8.5-fold $(P<0.001)$ compared to those in the Control group and 4.0-fold $(P<0.001)$ compared to those in the R1 group in the LD season. 
In the SD photoperiod, treatment with a high dose of rbresistin increased SOCS-3 expression 5.8-fold $(P<0.001)$ compared to the control group and 4.8-fold $(P<0.001)$ compared to the R1-group in the pituitary (Figure 4).

A.

- Control $\quad \square \mathrm{R} 1 \quad \square \mathrm{R} 2$

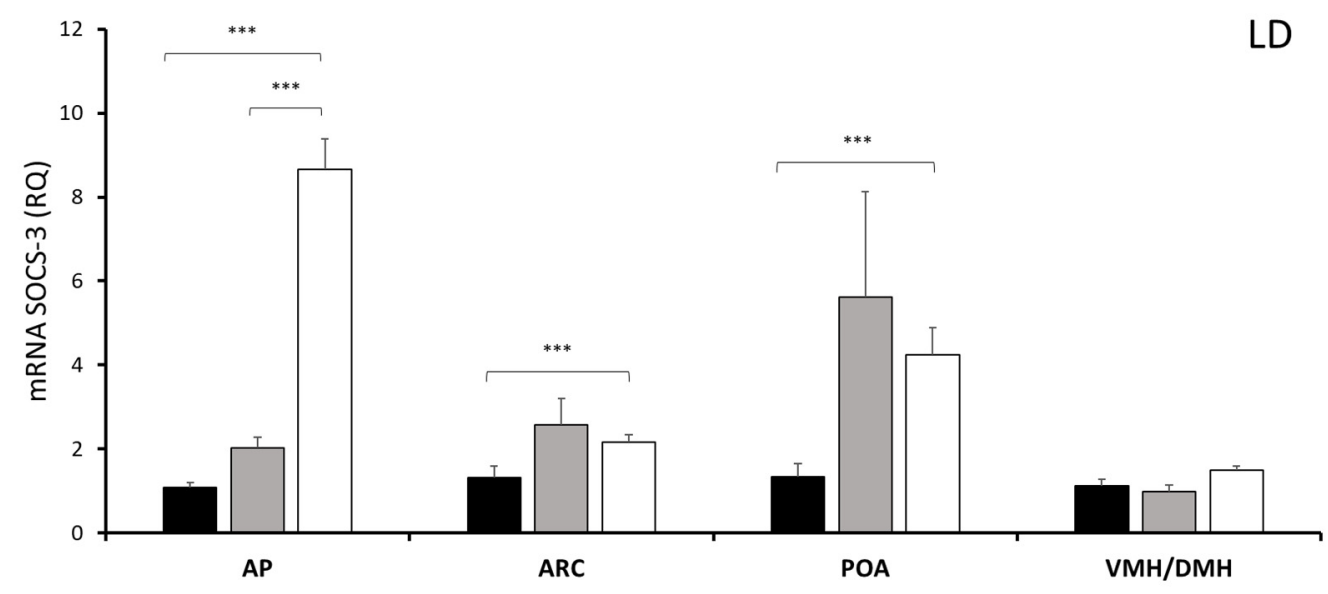

B.

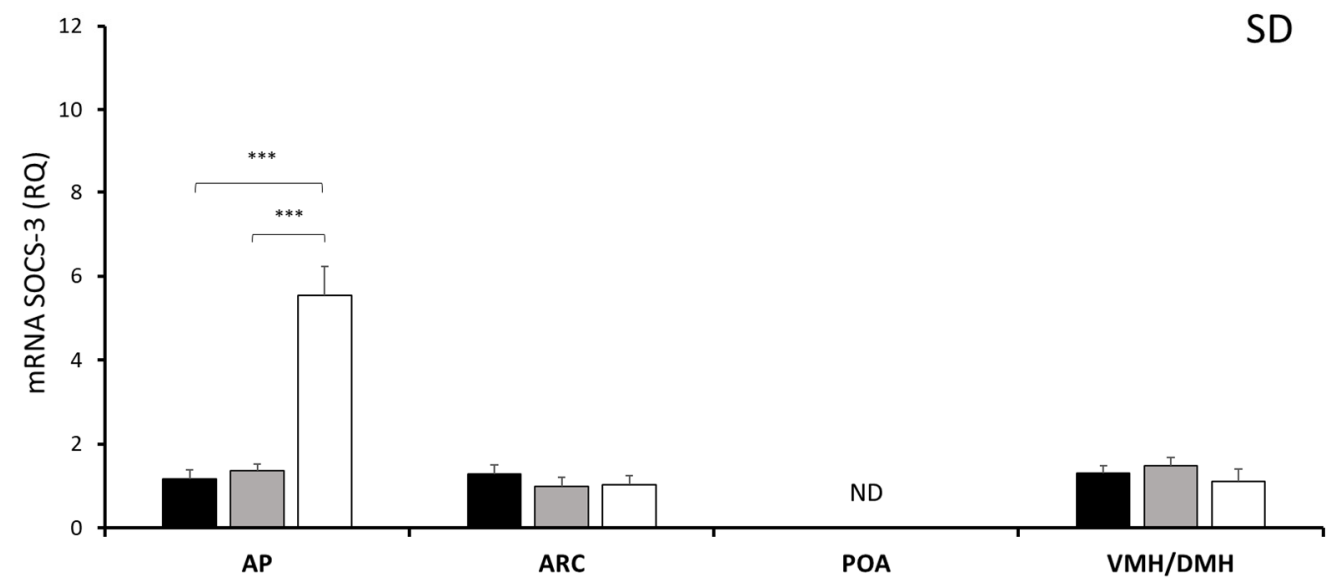

Figure 4. Expression of SOCS-3. The mean expression $( \pm \mathrm{SEM})$ of a suppressor of cytokine signaling-3 (SOCS-3) mRNA in the ovine anterior pituitary (AP), arcuate nucleus (ARC), preoptic area (POA) and ventro- and dorsomedial nuclei (VMH/DMH) collected during long-day (LD) (panel A) and short-day (SD) (panel B) photoperiods. The expression of SOCS-3 mRNA is reported in arbitrary units (RQ) relative to cyclophilin mRNA and expressed relative to the calibrator sample. Differences relative to the control or between the other groups are indicated with ${ }^{* * *} P<0.001$. Samples in which the expression of the target gene was undetectable are designated with ND.

The expression of SOCS-3 was detectable in almost all examined hypothalamic tissues, with one exception: no SOCS-3 transcript was detected in the POA during the SD season. During the LD season, within the ARC, SOCS-3 mRNA levels increased significantly $(P<0.001)$ after the injection of a high dose of rbresistin compared to the levels noted after the control treatment (Figure 4). No differences $(P \geq 0.05)$ were observed during the SD season. In the LD and SD seasons, no differences $(P \geq 0.05)$ were found in SOCS-3 transcript levels in the $\mathrm{VMH} / \mathrm{DMH}$ between rbresistin and control treatments or between the R1 and R2 groups (Figure 4). 


\section{Discussion}

The results of the experiments demonstrated for the first time the in vitro and in vivo effects of exogenous resistin on leptin concentrations in sheep. Furthermore, for the first time, resistin doseand photoperiod-related changes in the expression of the essential components of the leptin signaling pathway have been determined; LeptRb and the key negative regulator SOCS-3 in the anterior part of the pituitary, $\mathrm{VMH} / \mathrm{DMH}, \mathrm{ARC}$, and hypothalamic nuclei play pivotal roles in appetite regulation, and in the POA, a part of the anterior hypothalamus that possesses leptin neurons and controls energy homeostasis, which is critical to maintaining proper BW and temperature [24].

The first specific aim of our study was to confirm whether central leptin resistance occurs as a consequence of the hyperleptinemia caused by resistin treatment in sheep. Studies carried out by Asterholm et al. [11] demonstrated elevated resistin concentrations and significantly higher circulating leptin concentrations in transgenic mice, suggesting a new mechanism in which metabolic effects are dependent on resistin. In our study, regardless of the treatment (saline or resistin), the circulating concentration of leptin was higher in the period of lengthening days than during the period of shortening days-a phenomenon that is termed physiological central leptin resistance [1]. In seasonal breeding, leptin concentrations are higher in sheep when the days become longer than when days become shorter [4]. This phenomenon has been known since 2001; during the LD period in sheep, the leptin concentration in the bloodstream is elevated by $180 \%$ in contrast to the SD [4], but this change is not related to the appetite-lowering effect of leptin. At this time, when readily accessible food is abundant, sheep have an increased appetite and seem to be insensitive to high leptin levels that result from larger amounts of adipose tissue [4]. In our experiments, intravenous treatments with high and low doses of rbresistin significantly elevated leptin concentrations compared to the control treatment during both seasons. These results support the findings of Asterholm et al. [11] in a study of transgenic mice. However, Maillard et al. [25] and Asterholm et al. [11] emphasized the importance of the amount of resistin administered to the animals. The authors noticed a clear difference between the chronic high resistin concentrations in the transgenic mice and those resulting from acute treatment using a pharmacological dose of resistin in another study [11,25]. In the present study, we treated sheep with acute doses of 1.0 or $10 \mu \mathrm{g}$ of rbresistin per $\mathrm{kg}$ of BW. The doses of rbresistin used increased the circulating resistin concentration, though not above $16 \mathrm{ng} / \mathrm{mL}$, which does not exceed the plasma concentration described for cattle and sheep $(10-30 \mathrm{ng} / \mathrm{mL})$ [26]. Therefore, we noted that the effect of resistin can be considered physiological. In the present study, we highlight that hyperleptinemia induced by resistin was shown to be a potential hallmark of central leptin insensitivity.

In our ex vivo study, only one dose of recombinant resistin, the highest dose, significantly increased the leptin concentration in the media when cultures were performed during the LD photoperiod, and no other effect was observed. We carried out ovine perirenal adipose explants in vitro using an air-media interface, as we have successfully performed previously [5]. The response of adipose tissue to resistin was expected, particularly during the LD photoperiod; however, only one dose affected the leptin concentration. Many authors have observed that the acute pharmacological effects of hormones often trigger somewhat contradictory results under some circumstances $[11,25]$. The differences in the action of exogenous resistin between our in vitro and in vivo experiments can be caused by the ligand doses and the conditions of the study. Considering the results of in vitro studies with resistin by other groups, the use of tissue- and species-specific resistin for cell/tissue treatment needs more attention and consideration [25]. In a study on primary culture cells collected from bovine ovaries, Spicer et al. [22] observed a weak or no effect of resistin (recombinant mouse resistin) on thecal cell number and steroid secretion by large and small follicles. Resistin (rat resistin) demonstrated no effects on gonadotropin- or IGF-1-induced steroid secretion from porcine follicles in a 24-h culture compared to control conditions, as noted by Rak et al. [27]. The results of our previous experiments [12] and present experiments indicate that rbresistin is highly bioactive in sheep. The amino acid sequence of resistin is quite homologous in ruminant species; for example, bovine resistin is $91.21 \%$ homologous to ovine resistin [12]. There are only eight amino acid differences between them. Furthermore, the effects 
of resistin depend on binding to its cognate receptors. Although discovered in 2001, the functional receptor for resistin remains elusive, and further research is required to discover receptors for resistin in different species and their specific localization.

Leptin is well known to act mainly in brain regions where a significant number of LeptRb-expressing neurons are present, and areas with exceptionally high LeptRb expression are found in several places in the brain (midbrain, hypothalamus, and brainstem) $[15,28]$. Every group of LeptRb neurons within the ARC/VMH/DMH circuit supposedly gives certain information relevant to a specific set of inputs and outputs. Each of these brain regions plays a different role in energy homeostasis. The ARC neurons receive information about every small change in insulin, ghrelin and circulating nutrients, as well as leptin, to signal acute peripheral nutritional status. The DMH nuclei do not obtain information about acute changes in the peripheral nutrition status because of the existence of the blood-brain barrier [29] but collect information about the temperature of the body (with POA, where we can find another set of LeptRb neurons), along with information from leptin about long-term energy status [30]. The VMH, which is rich in glucose-sensing neurons, and the LeptRb neurons in this nucleus may also participate in glucose homeostasis regulation [31,32]. The results showed that in those hypothalamic nuclei (with the exception of the POA), exogenous resistin treatment decreased the expression of leptin receptors in a dose-related manner. We reported the approximate effect of leptin on LH secretion in cattle in 2003 [9], with a low dose having a stronger effect on LH compared to a higher dose of peptide; no effect was observed for the highest dose. It seems possible that a high rbresistin concentration can have detrimental effects on the number of LeptRb, and lower expression of the receptor was observed. Furthermore, the differences in resistin action were noticed according to season. Decreasing LeptRb expression with resistin can be speculated to reduce hypothalamic leptin responsiveness and cause central leptin resistance. In our study, acute resistin treatment upregulated LeptRb expression in the POA during the SD season. The neurons in the POA receive a signal about the outside atmospheric conditions and are activated by the low temperature [24]. The POA projects to other nuclei of the hypothalamus, such as the $\mathrm{VMH} / \mathrm{DMH}$, which are also engaged in the stimulation of thermogenesis in adipocytes of white and/or brown adipose tissue. POA LeptRb signaling has been indicated to modulate energy output depending on the internal energy state and thus help to maintain homeostasis of BW [24]. In sheep, the elevated expression of LeptRb in the POA during the SD season seems to be required for the regulation of food intake, which depends on the ambient temperature, as demonstrated previously $[33,34]$.

In seasonally breeding animals, the photoperiod primes the sensitivity of the hypothalamic nuclei to the concentration of leptin by modifying the expression of SOCS-3 within the neurons [1]. Another objective of the present study was to evaluate whether exogenous resistin is able to modulate the expression of SOCS-3 in different brain regions in relation to the dose of resistin and day length. Observations by Asterholm et al. [11] indicated how chronic resistin overexpression in transgenic mice affected central leptin resistance and reduced the expression of the inhibitors of leptin signaling - SOCS-3-in the hypothalamic nuclei. Studies carried out previously by our group in sheep have implicated SOCS-3 as a main factor by which leptin negatively affects its own signaling cascade and as a creator of leptin LD central resistance [5,7]. In 2005, Steppan et al. [19] showed, in cultured adipocytes in vitro as well as in adipose tissue, that resistin increases SOCS-3 mRNA expression in a time- and dose-related manner. These results suggest that SOCS-3 affects the capacity of resistin to alienate insulin and leptin activity in cells of adipose tissue [19]. Here, we discuss further evidence that supports the role of a specific member of the SOCS family of proteins, SOCS-3, and its role in resistin-mediated central leptin insensitivity. The expression of SOCS-3 was significantly detected in selected hypothalamic nuclei excluding the POA during the SD season. The lack of detection of SOCS-3 expression in POA during the SD season may result from very weak expression that is commonly demonstrated outside the medio-basal hypothalamus (ARC/VMD/DMH), as shown in field voles, a seasonal species [35], and rodents [36]. 
During the LD season, SOCS-3 transcript expression was significantly upregulated in the AP, ARC, and POA by a high dose of resistin. A low rbresistin dose caused too much variation in the response of ARC and POA; thus, even though an increase in SOCS-3 expression was noted, the differences between treatment groups were not significant. Based on these findings, we can report that an interaction with resistin contributes to the selective leptin resistance noted at the level of the pituitary gland and hypothalamus in sheep. The results indicate that resistin induced a consistent decrease in LeptRb (except for POA) and an increase in SOCS-3 expression during the LD season in all hypothalamic nuclei. In the AP, resistin increased SOCS-3 levels during both the LD and SD photoperiods, and the LeptRb transcript was increased only during the LD photoperiod. These results suggest that the leptin and resistin signaling pathways are integrated with the LeptRb and SOCS-3 proteins. In agreement with these results, we observed a merger between leptin and resistin-induced expression of SOCS-3 in the pituitary gland and ARC during SDs and in the ARC during LDs in a previous study $[7,19]$. The SOCS-3 protein was demonstrated to potentially be involved in leptin and resistin interactions. Furthermore, this study indicates how photoperiod affects the effects of resistin on adjusting energy expenditures and energy resources in seasonal organisms.

\section{Conclusions}

To conclude, our data support the hypothesis that resistin elevates leptin concentrations and cooperates with leptin in increasing tissue SOCS-3 expression and lowering LeptRb transcript levels, contributing to decreasing central leptin responsiveness in the brain according to photoperiod. Collectively, these findings show that resistin may be another factor that is involved in central leptin resistance. Further understanding of the mechanisms regulating energy homeostasis and endocrine interactions between leptin and resistin in a large animal model is essential. To date, only a few studies have provided results from in vivo experiments using resistin.

Author Contributions: Conceptualization, D.A.Z. and W.B.; Data curation, M.S. and K.K.; Formal analysis, M.S. and K.K.; Methodology, D.A.Z., W.B. and T.M.; Project administration, D.A.Z. and W.B.; Writing一original draft, D.A.Z. and W.B.; Writing-review and editing, D.A.Z. and W.B.

Funding: A grant obtained from the National Science Center (2015/19/B/NZ9/01314) supported this work.

Acknowledgments: The authors sincerely thank Dr. Katarzyna Romanowicz and Anna Borsuk for technical assistance.

Conflicts of Interest: No conflicts of interest are declared by authors.

\section{References}

1. Adam, C.L.; Mercer, J.G. Appetite regulation and seasonality: Implications for obesity. Proc. Nutr. Soc. 2004, 63, 413-419. [CrossRef] [PubMed]

2. Verhoeven, G.E.M.; Wilson, J.D. The syndromes of primary hormone resistance. Metabolism 1979, 28, $253-289$. [CrossRef]

3. Banks, W.A. Role of the blood-brain barrier in the evolution of feeding and cognition. Ann. N. Y. Acad. Sci. 2012, 1264, 13. [CrossRef] [PubMed]

4. Marie, M.; Findlay, P.A.; Thomas, L.; Adam, C.L. Daily patterns of plasma leptin in sheep: Effects of photoperiod and food intake. J. Endocrinol. 2001, 170, 277-286. [CrossRef] [PubMed]

5. Szczesna, M.; Zieba, D.A.; Klocek-Gorka, B.; Misztal, T.; Stepien, E. Seasonal effects of central leptin infusion and prolactin treatment on pituitary SOCS-3 gene expression in ewes. J. Endocrinol. 2011, 208, 81-88. [CrossRef]

6. Szczesna, M.; Kirsz, K.; Misztal, T.; Zieba, D.A. Downregulation of LRb in VMH/DMH during the second half of gestation and upregulation of SOCS-3 in ARC in late-pregnant ewes-Implications for leptin resistance. Gen. Comp. Endocrinol. 2019, 274, 73-79. [CrossRef] [PubMed]

7. Zieba, D.A.; Szczesna, M.; Klocek-Gorka, B.; Molik, E.; Misztal, T.; Williams, G.L.; Romanowicz, K.; Stepien, E.; Keisler, D.H.; Murawski, M. Seasonal effects of central leptin infusion on secretion of melatonin and prolactin and on SOCS-3 gene expression in ewes. J. Endocrinol. 2008, 198, 147-155. [CrossRef] 
8. Gruzdeva, O.; Borodkina, D.; Uchasova, E.; Dyleva, Y.; Barbarash, O. Leptin resistance: Underlying mechanisms and diagnosis. Diabetes Metab. Syndr. Obes. 2019, 12, 191-198. [CrossRef]

9. Zieba, D.A.; Amstalden, M.; Maciel, M.N.; Keisler, D.H.; Raver, N.; Gertler, A.; Williams, G.L. Divergent effects of leptin on luteinizing hormone and insulin secretion are dose dependent. Exp. Biol. Med. Maywood 2003, 228, 325-330. [CrossRef]

10. Zieba, D.A.; Amstalden, M.; Morton, S.; Gallino, J.L.; Edwards, J.F.; Harms, P.G.; Williams, G.L. Effects of leptin on basal and GHRH-stimulated GH secretion from the bovine adenohypophysis are dependent upon nutritional status. J. Endocrinol. 2003, 178, 83-89. [CrossRef]

11. Asterholm, I.W.; Rutkowski, J.M.; Fujikawa, T.; Cho, Y.R.; Fukuda, M.; Tao, C.; Wang, Z.V.; Gupta, R.K.; Elmquist, J.K.; Scherer, P.E. Elevated resistin levels induce central leptin resistance and increased atherosclerotic progression in mice. Diabetologia 2014, 57, 1209-1218. [CrossRef] [PubMed]

12. Biernat, W.; Kirsz, K.; Szczesna, M.; Zieba, D.A. Resistin regulates reproductive hormone secretion from the ovine adenohypophysis depending on season. Domest. Anim. Endocrinol. 2018, 65, 95-100. [CrossRef] [PubMed]

13. Dall'Aglio, C.; Scocco, P.; Maranesi, M.; Petrucci, L.; Acuti, G.; De Felice, E.; Mercati, F. Immunohistochemical identification of resistin in the uterus of ewes subjected to different diets: Preliminary results. Eur. J. Histochem. 2019, 63, 3020. [CrossRef] [PubMed]

14. Elmquist, J.K.; Bjrbk, C.; Ahima, R.S.; Flier, J.S.; Saper, C.B. Distributions of leptin receptor mRNA isoforms in the rat brain. J. Comp. Neurol. 1998, 395, 535-547. [CrossRef]

15. Elias, C.F.; Kelly, J.F.; Lee, C.E.; Ahima, R.S.; Drucker, D.J.; Saper, C.B.; Elmquist, J.K. Chemical characterization of leptin-activated neurons in the rat brain. J. Comp. Neurol. 2000, 423, 261-281. [CrossRef]

16. Woods, A.J.; Stock, M.J. Leptin activation in hypothalamus. Nature 1996, 381, 745. [CrossRef] [PubMed]

17. Habeeballah, H.; Alsuhaymi, N.; Stebbing, M.J.; Jenkins, T.A.; Badoer, E. Central leptin and resistin combined elicit enhanced central effects on renal sympathetic nerve activity. Exp. Physiol. 2016, 101, 791-800. [CrossRef] [PubMed]

18. Kosari, S.; Rathner, J.A.; Chen, F.; Kosari, S.; Badoer, E. Centrally administered resistin enhances sympathetic nerve activity to the hindlimb but attenuates the activity to brown adipose tissue. Endocrinology 2011, 152, 2626-2633. [CrossRef] [PubMed]

19. Steppan, C.M.; Wang, J.; Whiteman, E.L.; Birnbaum, M.J.; Lazar, M.A. Activation of SOCS-3 by resistin. Mol. Cell. Biol. 2005, 25, 1569-1575. [CrossRef] [PubMed]

20. Russel, A.J.F.; Doney, J.M.; Gunn, R.G. Subjective assessment of body fat in live sheep. J. Agric. Sci. 2009, 72, 451-454. [CrossRef]

21. Norms, R.R.R. Nutrient Requirements for Cattle and Sheep in the Traditional System, 6th ed.; IZ: Krakow, Poland, 1993.

22. Spicer, L.J.; Schreiber, N.B.; Lagaly, D.V.; Aad, P.Y.; Douthit, L.B.; Grado-Ahuir, J.A. Effect of resistin on granulosa and theca cell function in cattle. Anim. Reprod. Sci. 2011, 124, 19-27. [CrossRef] [PubMed]

23. Delavaud, C.; Bocquier, F.; Chilliard, Y.; Keisler, D.H.; Gertler, A.; Kann, G. Plasma leptin determination in ruminants: Effect of nutritional status and body fatness on plasma leptin concentration assessed by a specific RIA in sheep. J. Endocrinol. 2000, 165, 519-526. [CrossRef] [PubMed]

24. Yu, S.; Cheng, H.; Francois, M.; Qualls-Creekmore, E.; Huesing, C.; He, Y.; Jiang, Y.; Gao, H.; Xu, Y.; Zsombok, A.; et al. Preoptic leptin signaling modulates energy balance independent of body temperature regulation. Elife 2018, 7, e33505. [CrossRef] [PubMed]

25. Maillard, V.; Elis, S.; Desmarchais, A.; Hivelin, C.; Lardic, L.; Lomet, D.; Uzbekova, S.; Monget, P.; Dupont, J. Visfatin and resistin in gonadotroph cells: Expression, regulation of LH secretion and signaling pathways. Reprod. Fertil. Dev. 2017, 29, 2479-2495. [CrossRef] [PubMed]

26. Reverchon, M.; Rame, C.; Cognie, J.; Briant, E.; Elis, S.; Guillaume, D.; Dupont, J. Resistin in dairy cows: Plasma concentrations during early lactation, expression and potential role in adipose tissue. PLoS ONE 2014, 9, e93198. [CrossRef] [PubMed]

27. Rak, A.; Drwal, E.; Karpeta, A.; Gregoraszczuk, E.L. Regulatory role of gonadotropins and local factors produced by ovarian follicles on in vitro resistin expression and action on porcine follicular steroidogenesis. Biol. Reprod. 2015, 92, 142. [CrossRef] [PubMed]

28. Leshan, R.L.; Bjornholm, M.; Munzberg, H.; Myers, M.G., Jr. Leptin receptor signaling and action in the central nervous system. Obesity 2006, 14, 208S-212S. [CrossRef] [PubMed] 
29. Faouzi, M.; Leshan, R.; Bjornholm, M.; Hennessey, T.; Jones, J.; Munzberg, H. Differential accessibility of circulating leptin to individual hypothalamic sites. Endocrinology 2007, 148, 5414-5423. [CrossRef]

30. Thompson, R.; Swanson, L. Structural characterization of a pattern hypothalamic visceromotor generator network. Brain Res. Rev. 2003, 41, 153-202. [CrossRef]

31. King, B.M. The rise, fall, and resurrection of the ventromedial hypothalamus in the regulation of feeding behavior and body weight. Physiol. Behav. 2006, 87, 221-244. [CrossRef]

32. Tong, Q.; Ye, C.; McCrimmon, R.J.; Dhillon, H.; Choi, B.; Kramer, M.D.; Yu, J.; Yang, Z.; Christiansen, L.M.; Lee, C.E.; et al. Synaptic glutamate release by ventromedial hypothalamic neurons is part of the neurocircuitry that prevents hypoglycemia. Cell. Metab. 2007, 5, 383-393. [CrossRef] [PubMed]

33. Kaiyal, K.J.; Ogimoto, K.; Nelson, J.T.; Muta, K.; Morton, G.J. Physiological role for leptin in the control of thermal conductance. Mol. Metab. 2016, 5, 892-902. [CrossRef] [PubMed]

34. Kaiyala, K.J.; Ogimoto, K.; Nelson, J.T.; Schwartz, M.W.; Morton, G.J. Leptin signaling is required for adaptive changes in food intake, but not energy expenditure, in response to different thermal conditions. PLoS ONE 2015, 10, e0119391. [CrossRef] [PubMed]

35. Król, E.; Tups, A.; Archer, Z.A.; Ross, A.W.; Moar, K.M.; Bell, L.M.; Duncan, J.S.; Mayer, C.; Morgan, P.J.; Mercer, J.G.; et al. Altered expression of SOCS3 in the hypothalamic arcuate nucleus during seasonal body mass changes in the field vole, Microtus agrestis. J. Neuroendocrinol. 2007, 19, 83-94. [CrossRef] [PubMed]

36. Matarazzo, V.; Schaller, F.; Nédélec, E.; Benani, A.; Pénicaud, L.; Muscatelli, F.; Moyse, E.; Bauer, S. Inactivation of SOCS3 in the hypothalamus enhances the hindbrain response to endogenous satiety signals via oxytocin signaling. J. Neurosci. 2012, 32, 17097-17107. [CrossRef] [PubMed]

(C) 2019 by the authors. Licensee MDPI, Basel, Switzerland. This article is an open access article distributed under the terms and conditions of the Creative Commons Attribution (CC BY) license (http://creativecommons.org/licenses/by/4.0/). 